\title{
Effect of Daily Supplementation of Isoflavones on Clinical Symptoms of Post-Menopausal Indian Women at a Tertiary Referral Center
}

\author{
Venkatesh Mootha ${ }^{1}$, Kameswari Kolluru \\ ${ }^{1}$ Proffessor, Department of Pharmacology, NRI Institute of Medical Sciences, Vishakapatnam, India \\ ${ }^{2}$ Assisstant Professor, Department of Obstetrics and Gynaecology, Konaseema Institute of Medical Sciences, Amalapuram, India
}

\begin{abstract}
The aim of this study was to evaluate the effectiveness of a pharmaceutical grade isoflavone supplement (1500IU) (Meno pro, British biologicals, India) on the number of hot flashes and night sweats in menopausal Indian women. This open, prospective study involved 126 post-menopausal women with climacteric symptoms. These patients were randomised to receive either the isoflavone supplementation or placebo and the patients were followed up over a 12 week period. The outcome measure was fewer hot flashes and night sweats. The incidence of hot flushes significantly reduced from 5.87 episodes /day to 1.75 episodes / day in the isoflavone group while the reduction was not much in the placebo group. Similarly the frequency of night sweats reduced significantly from 2.77 episodes / night to 1.14 episodes / night in the isoflavone group. These results confirm the effectiveness of a pharmaceutical grade isoflavone supplement on vasomotor symptoms in menopausal women.
\end{abstract}

Keywords: Post menopause, Phytoestrogens, Isoflavones, Night sweats, Hot flushes

\section{Introduction}

The most common symptoms associated with menopause include vasomotor instability, decreased libido, vaginal dryness, insomnia, and bone or joint disorders. Hot flashes are a vasomotor response to estrogen deficiency, which generally appears up to five years after the end of menstruation [1]. Hot flashes and sweating are estimated to affect $80 \%$ of the female population in Western countries. However, this prevalence is lower in Southeast Asian populations [2]. Menopausal women often consider hot flashes to be the most difficult symptom to tolerate. These vasomotor-related effects can greatly impact the quality of life [3]. Hormone replacement therapy (HRT) remains the most effective treatment for vasomotor instability during menopause [4]. Recent data on the side-effects of HRT, including venous thromboembolism and potential breast cancer risks, raised concern in the community. These reservations concerning HRT, together with greater community awareness and increasing availability and enthusiastic marketing of alternative products have resulted in ever-increasing usage of natural therapies. Phytoestrogens are naturally occurring nonsteroidal plant compounds that have both estrogenic and anti-estrogenic activity. There are three main classes of phytoestrogens: coumestans, lignans and isoflavones [5].

In the current study we aimed to determine the effects of consuming isoflavone supplement for 12 Weeks on the incidence of hot flushes and night sweats in post-menopausal Indian women.

\section{Material and Methods}

The study is a prospective randomised case control study which was conducted from June 2015 to December 2016. A total of 126 post-menopausal women are included in the study. Randomisation was performed based on random charts and throughout the study blinding of both the patients and observer was maintained. To be included in the study, patients had to be menopausal for at least one year and to experience at least five episodes of hot flashes per day and/or moderate to severe night sweats every day. Women with past or family history of breast cancer, VTE and previous hip or vertebral fractures or surgery were excluded.

Participants were randomly assigned to receive daily either a isoflavone supplementation powder $30 \mathrm{gms} /$ day (Protein(28 G), Carbohydrate(55 G), Vitamin $\mathrm{E}(300$ IU), Vitamin $\mathrm{K}(100 \mathrm{Mcg})$, Vitamin $\mathrm{D}(10 \mathrm{Mcg})$, Isoflavone(1500IU) (Meno pro, British biologicals, India) or a placebo of identical appearance (which contained similar ingridients except for isoflavones for 12 weeks.

Evaluation criteria included the number of hot flashes and daily episodes of night sweats during the study. The data collected on hot flashes and night sweats were daily, but were grouped per week for analysis. We calculated mean number of hot flashes and/or daily night sweats during the 12 weeks of the study and represented these graphically using Excel spread sheet. Only women who finished the study were included in the effectiveness analysis.

\section{Results}

All together of 126 women were enrolled in to the study, however only 114 women completed the treatment protocol for complete 12 weeks and were able to maintain the clinical symptom dairies. Comparison of baseline parameters among the control and placebo groups is shown in table 1 . 


\section{International Journal of Science and Research (IJSR) \\ ISSN (Online): 2319-7064}

Index Copernicus Value (2016): 79.57 | Impact Factor (2015): 6.391

Table 1: Comparison of baseline parameters among the 2 groups (Isoflavone group and placebo group)

\begin{tabular}{|c|c|c|c|}
\hline Parameter & $\begin{array}{c}\text { Isoflavone } \\
\text { group (n-57) }\end{array}$ & $\begin{array}{c}\text { Placebo } \\
\text { group (n-57) }\end{array}$ & P value \\
\hline Age & $\begin{array}{c}57.04 \pm 3.32 \\
\text { yrs }\end{array}$ & $\begin{array}{c}56.27 \pm 3.85 \\
\text { yrs }\end{array}$ & $>0.05$ \\
\hline Post menopausal<2 yrs & 25 & 24 & $>0.05$ \\
\hline Post menopausal>2 yrs & 32 & 33 & $>0.05$ \\
\hline No. of Hot flushes / day & $5.87 \pm 1.66$ & $5.96 \pm 1.03$ & $>0.05$ \\
\hline No. of night sweats / day & $2.77 \pm 0.68$ & $2.89 \pm 0.61$ & $>0.05$ \\
\hline
\end{tabular}

The incidence of hot flushes significantly reduced from 5.87 episodes /day to 1.75 episodes / day in the isoflavone group while the reduction was not much in the placebo group. Similarly the frequency of night sweats reduced significantly from 2.77 episodes / night to 1.14 episodes / night in the isoflavone group. (Table. 2)

Table 2: Comparison of clinical symptoms in both the groups at the end of 16 weeks

\begin{tabular}{|c|c|c|c|}
\hline Parameter & $\begin{array}{c}\text { Isoflavone } \\
\text { group (n-57) }\end{array}$ & $\begin{array}{c}\text { Placebo group } \\
\text { (n-57) }\end{array}$ & $\begin{array}{c}\mathrm{P} \\
\text { value }\end{array}$ \\
\hline No. of Hot flushes / day & $1.75 \pm 0.43$ & $5.80 \pm 1.00$ & 0.00 \\
\hline No. of night sweats / day & $1.14 \pm 0.61$ & $2.66 \pm 0.74$ & 0.00 \\
\hline
\end{tabular}

\section{Discussion}

A number of interventional studies have investigated the role of phytoestrogens, principally from soy, in the treatment of menopausal symptoms, with conflicting results. Murkies and colleagues demonstrated that 12 weeks of taking soy flour and wheat flour decreased hot flushes by $40 \%$ and $25 \%$, respectively, but the difference between the groups was not significant [6]. The specific effects of soy supplementation on hot flushes remain controversial. A significant improvement of flushes was noted in a randomized doubleblind placebo-controlled trial by Washburn and associates, who compared complex carbohydrates with soy protein [7].

In the current study we are able to clearly demonstrate the positive effect of phytohormones on the clinical postmenopausal symptoms like hot flushes and night sweats. The incidence of hot flushes significantly reduced from 5.87 episodes /day to 1.75 episodes / day and similarly the frequency of night sweats reduced significantly from 2.77 episodes / night to 1.14 episodes / night after isoflavone supplementation for 12 weeks.

Recently, studies by Baber and Knight and their colleagues used concentrated subfractions of isoflavones from red clover in oral tablet form compared to matching placebo and investigated the effects of phytoestrogens on menopausal symptoms. In both cases there was no significant improvement in menopausal symptoms between the active and placebo groups [8]. Although the effects of phytoestrogens on menopausal symptoms remains controversial, one unequivocal finding emerging from these studies is the substantial placebo effect, mandating that all studies in this area need to be controlled.

The strength of our study is that it is a randomized case control study. These results confirm the efficacy of a pharmaceutical gradeisoflavone supplement on vasomotor disorders in menopausal Indian patients. Specifically, we found that our treatment led to a significant decrease in the number of hot flashes and night sweats while displaying very good long-term tolerance.

\section{References}

[1] Nelson, H.D. Menopause. Lancet,2008; 371: 760-770

[2] Gold, E.B., Colvin, A., Avis, N., Bromberger, J., Greendale, G.A., Powell, L., et al. Longitudinal analysis of the association between vasomotor symptoms and race/ ethnicity across the menopausal transition: Study of women's health across the nation. American Journal of Public Health, 2006; 96: 1226-1235.

[3] Rodstrom, K., Bengtsson, C., Lissner, L., Milsom, I.Sundh, V., Bjorkelund, C.A. Longitudinal study of the treatment of hot flushes: The population study of women in Gothenburg during a quarter of a century. Menopause, 2002; 9: 156-161.

[4] Eden, J. Phytoestrogens and the menopause.Baillière's Clinical Endocrinology and Metabolism,1998; 12: 581587.

[5] Murkies AL, Wilcox G, Davis SR. Phytoestrogens. J ClinEndocrinolMetab 1998;83: 297-303

[6] Murkies AL, Lombard C, Strauss BJG,et al. Dietary flour supplementation decreases postmenopausal hot flushes: effect of soy and wheat. Maturitas1995;21:18995

[7] Washburn S, Gregory L, Burke MD,et al. Effect of soy protein supplementation on serum lipoproteins, blood pressure, and menopausal symptoms in perimenopausal women. Menopause 1999;6:7-13

[8] Knight DC, Howes JB, Eden JA. The effect of Promensil, an isoflavone extract, on menopausal symptoms.Climacteric1999;2:79-84

\section{Author Profile}

Venkatesh Mootha did MBBS from Rangaraya Medical college, Kakinada and MD Pharmoclogy from Rangaraya Medical College, Kakinada. He worked as Assisstant professor in the department of Pharmacology at KIMS, Amalapuram.

Kameswari Kolluru did MBBS from Andhra Medical College, Vishakapatnam and MD Obstetrics and Gynaecology from Rangaraya Medical College, Kakinada. She worked as senior resident in the department of Obstetrics and Gynaecology, KIMS, Amalapuram 